\title{
RNAi in fission yeast finds new targets and new ways of targeting at the nuclear periphery
}

\author{
Daniel Holoch and Danesh Moazed ${ }^{1}$ \\ Department of Cell Biology, Howard Hughes Medical Institute, Harvard Medical School, Boston, Massachusetts 02115, USA
}

RNAi in Schizosaccharomyces pombe is critical for centromeric heterochromatin formation. It has remained unclear, however, whether RNAi also regulates the expression of protein-coding loci. In the April 1, 2012, issue of Genes \& Development, Woolcock and colleagues (pp. 683-667) reported an elegant mechanism for the conditional RNAi-mediated repression of stress response genes involving association with Dcr1 at the nuclear pore. Unexpectedly, the initial targeting of RNAi components to these genes does not require small RNA guides.

Not long after it was discovered as a mechanism of dsRNA-mediated post-transcriptional gene silencing (Fire et al. 1998), it became evident that RNAi also regulates the genome at the level of transcription and chromatin structure in a wide range of organisms. Roles for RNAi have been identified in DNA elimination in Tetrahymena thermophila, RNA-directed DNA methylation in plants, and transcriptional gene silencing in Drosophila melanogaster, Caenorhabditis elegans, and the fission yeast Schizosaccharomyces pombe (Moazed 2009). In principle, RNAi could identify target loci through direct basepairing between its small RNA guides and DNA, but to date, only targeting via complementary RNA transcripts has been described. Consequently, RNAi-based regulation at the chromatin level is thought to involve the interaction of silencing proteins with nascent transcripts (Bühler and Moazed 2007; Lejeune and Allshire 2011). First described in $S$. pombe, this nascent transcript model is strongly supported by the finding that small RNAs can cause gene-specific arrest of elongating RNA polymerase II in C. elegans and RNA polymerase IV- and polymerase V-dependent DNA methylation in Arabidopsis thaliana (Wierzbicki et al. 2009; Guang et al. 2010).

Extensive evidence that nascent transcripts serve as targets of nuclear RNAi comes from studies in $S$. pombe, in which the genes encoding a Dicer dsRNA nuclease

[Keywords: RNAi; CTGS; NPC; stress response; thermoswitch; Atf1 transcription factor]

${ }^{1}$ Corresponding author.

E-mail danesh@hms.harvard.edu.

Article is online at http://www.genesdev.org/cgi/doi/10.1101/gad.191155.112. $\left(d c r 1^{+}\right)$, an Argonaute protein $\left(a g o 1^{+}\right)$, and an RNAdirected RNA polymerase $\left(r d p 1^{+}\right)$are each required for establishment and maintenance of centromeric heterochromatin (Volpe et al. 2002). Biochemical purifications showed that Agol acts within a chromatin-bound RNAinduced transcriptional silencing (RITS) complex (Verdel et al. 2004). Subsequent studies revealed that RITS interacts with noncoding centromeric transcripts and that artificially enforcing its binding to a nascent euchromatic RNA is sufficient to induce heterochromatic silencing of the corresponding locus (Motamedi et al. 2004; Bühler et al. 2006). Together, these results gave rise to the view that RNAi is recruited cotranscriptionally to its nuclear targets (Fig. 1A). Also consistent with this model are the observations that centromeric siRNA accumulation is disrupted in mutants of RNA polymerase II subunits or splicing factors (Djupedal et al. 2005; Bayne et al. 2008).

Although $S$. pombe has proved a uniquely powerful system for understanding RNAi-based silencing in the nucleus, the cotranscriptional gene silencing (CTGS) mechanism, suggested by the above studies, still presents several mysteries. Here, we focus in particular on two of them. First, in contrast to many other RNAi systems, it has been observed that $S$. pombe small RNAs alone do not robustly recruit the RNAi machinery to targeted loci, suggesting they must instead act in concert with other molecular signals (Fig. 1B). Second, the physiological regulation of protein-coding genes by RNAi in $S$. pombe has only recently begun to be appreciated.

A new study by Bühler and colleagues (Woolcock et al. 2012) offers exciting new insights into both of these questions. By probing the genome-wide localization of RNAi factors using the highly sensitive DNA adenine methyltransferase identification (DamID) technique, they uncover a role for RNAi in the regulation of a class of stress response genes associated with the DNA-binding protein Atf1 and nuclear pores. They present surprising and compelling evidence for small RNA-independent recruitment of RNAi components to their targets. Finally, they propose an attractive model that provides a structural basis for the conditional relocalization of Dcrl and concomitant derepression of stress-inducible genes. 
A

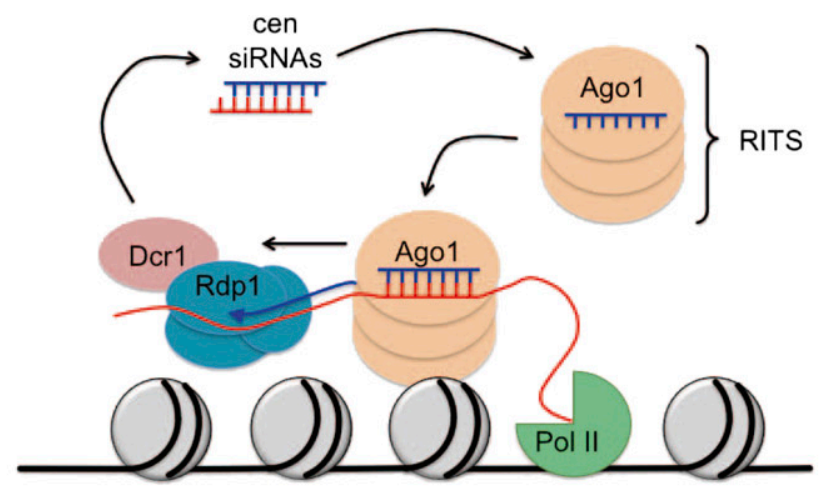

Centromeric repeats

B
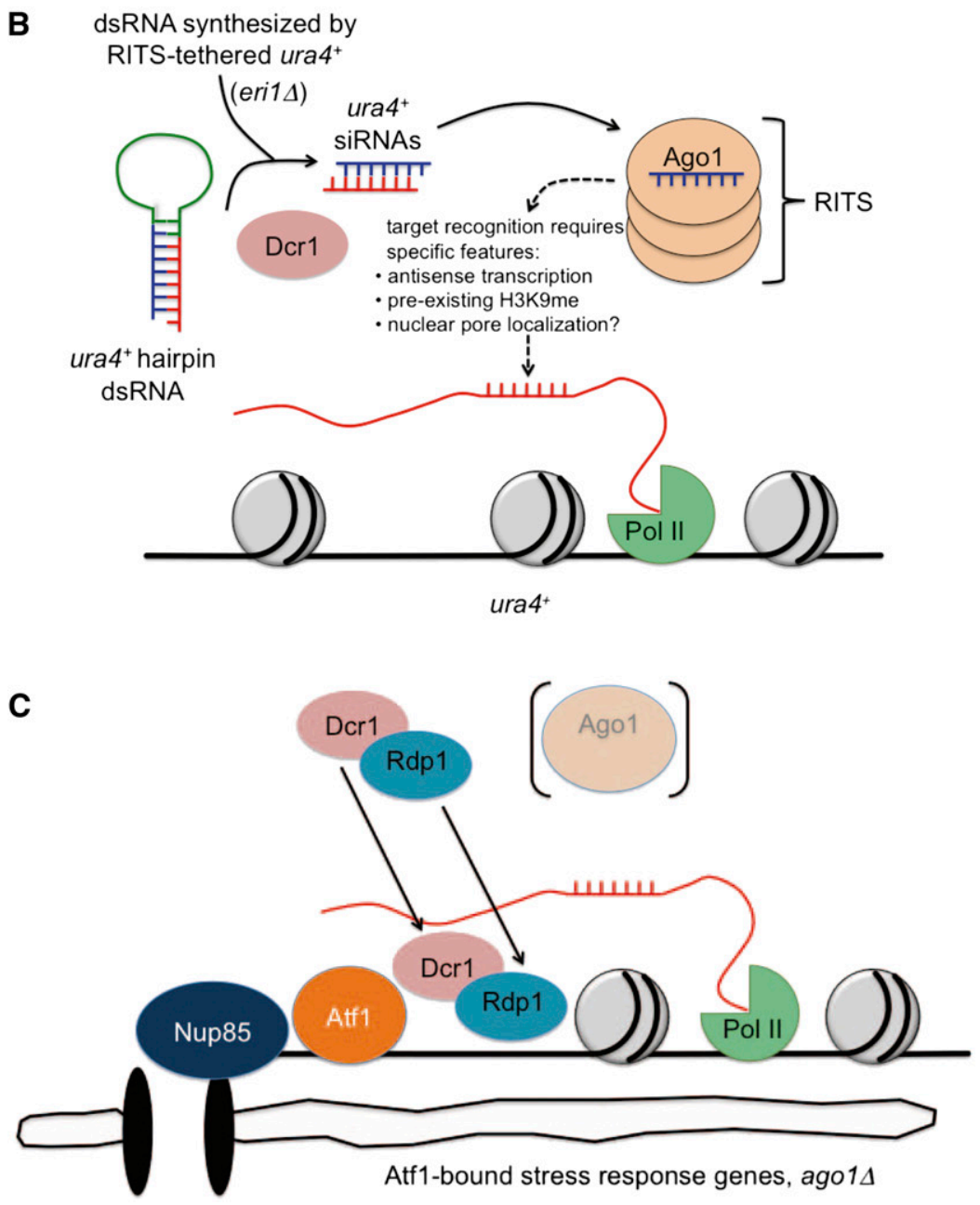

Figure 1. Models for target recognition by the $S$. pombe RNAi machinery. (A) At the robustly silenced centromeric repeats, siRNAs bound to the Agol subunit guide the RITS complex to complementary nascent RNA targets and corresponding sites on chromatin. RITS then promotes the recruitment of the RNA-dependent RNA polymerase complex (RDRC), containing Rdp1, and Dcrl. Small RNA guides are thus necessary for all targeting of the RNAi machinery to the centromeres. (B) Expression of ura $4^{+}$hairpin transcripts or tethering of RITS to $\mathrm{ura}^{+}{ }^{+}$RNA yields large pools of Dcrl-dependent ura4 ${ }^{+}$siRNAs that bind to the RITS complex, but the native ura $4^{+}$ locus is not targeted. Thus, small RNAs are not sufficient to trigger recruitment of the RNAi machinery to this gene. (C) The novel case of the Atf1-bound genes identified by Woolcock et al. (2012). Here, deletion of Ago1, the mediator of small RNA-guided sequence specificity, does not inhibit Dcr1 and Rdp1 recruitment to chromatin. Therefore, small RNAs are not necessary for the initial targeting of these loci.

\section{Small RNAs and the recruitment of the RNAi machinery}

In most organisms endowed with RNAi, short dsRNA molecules of $\sim 20-25$ nucleotides (nt) in length, often the products of a Dicer ribonuclease acting on endogenous or exogenous dsRNA substrates, are sufficient to trigger a sequence-specific silencing response (Meister and Tuschl 2004). Intriguingly, RNAi-mediated chromatin silencing in
S. pombe stands in stark contrast to this rule. For example, high levels of hairpin-derived, Dcr1-dependent siRNAs directed against the $u r a 4^{+}$gene are unable to elicit repression of the corresponding sequence in its native locus, despite being loaded into the RITS complex (Iida et al. 2008; Simmer et al. 2010). Instead, one or more other events are required to achieve hairpin-mediated silencing (see below). Similarly, when $\mathrm{ura}^{+}{ }^{+}$siRNAs are generated 
by tethering RITS to ura4 nascent transcripts, they fail to guide RITS to a second allele of ura4 introduced on another chromosome unless the gene encoding the Eri1 ribonuclease is deleted (Bühler et al. 2006). Together, these results imply that siRNAs are not the only necessary determinants of RNAi targeting in S. pombe.

There are currently several clues as to what, in addition to small RNAs themselves, might trigger the initial recruitment of RNAi components (Fig. 1B). One possibility is that a minimal level of methylation of histone $\mathrm{H} 3$ on Lys 9 (H3K9me), a key heterochromatic signature, is obligatory to stabilize RITS for de novo silencing (Iida et al. 2008; Schalch et al. 2009). Such a requirement, and possibly other features, could make certain genomic loci more susceptible than others to small RNA-guided targeting of RNAi factors. Consistent with this notion are independent observations that displacing $u r a 4^{+}$from its native locus can potentiate it for hairpin-mediated silencing (Iida et al. 2008; Simmer et al. 2010). Importantly, hairpinprogrammed silencing seems to be favored by the presence of antisense transcription or pre-existing $\mathrm{H} 3 \mathrm{~K} 9 \mathrm{me}$ at the targeted locus (Iida et al. 2008). A role for bidirectional transcription in targeting the RNAi machinery might also help explain why centromeric repeats are so robustly silenced. Indeed, the widespread presence of complementary transcripts appears to allow the repeats to be targeted by Ago1-bound primal RNAs even in the absence of Dcr1 (Halic and Moazed 2010).

The work of Woolcock et al. (2012) represents a sea change in our understanding of RNAi recruitment to chromatin. Extending previous DamID analyses that uncovered for the first time a physical association between Dcrl and the genome (Woolcock et al. 2011), the new results show that, remarkably, binding of Dcrl to both heterochromatin and euchromatin is unchanged in cells lacking Agol or Rdp1. Likewise, although Rdp1 association with heterochromatin requires Agol and Dcrl, consistent with previous chromatin immunoprecipitation data (Sugiyama et al. 2005), its euchromatic binding profile is very similar to that of Dcrl and is also unchanged when Ago1 or Dcrl is deleted. These findings reveal the existence of a mechanism for targeting components of the RNAi machinery to chromatin that is entirely distinct from previous models in that it does not rely on Agol or its small RNA guides (Fig. 1C). Until now, it has been taken for granted that small RNAs are indispensable, because deletion of Dcr1 abrogates the interactions of RITS and Rdp1 with one another and with centromeric repeats (Motamedi et al. 2004; Verdel et al. 2004; Sugiyama et al. 2005), but the DamID results from Woolcock et al. (2012) build a very different case for the euchromatic targets of RNAi and raise a host of new questions.

First, in addition to asking why siRNAs are not sufficient to recruit RNAi, we now are prompted to ask why they are not always necessary. In other words, if not siRNAs, what brings Dcr1 and Rdp1 to specific chromatin sites? The investigators attribute this phenomenon to the subnuclear colocalization of these proteins with targeted loci near the nuclear pore complex (NPC) (discussed below). It remains to be seen whether small RNAindependent targeting also occurs at loci not bound to nuclear pores. A second question regards the adaptive significance of this recruitment mechanism. Are Dcr1 and Rdp1 maintained at certain sites in order to keep the cell poised to preferentially amplify specific small RNA pools, or is the early timing of association prior to small RNA generation not critical for silencing itself? The investigators have uncovered an ideal system in which to study how physical targeting of RNAi might be uncoupled from repression and small RNA amplification.

\section{The role of subcellular localization in regulating the activity of RNAi}

Trafficking between the nucleus and cytoplasm has long been known to be instrumental in the cell's execution of RNAi. In the microRNA (miRNA) pathway, natively synthesized hairpin miRNA precursors undergo two successive processing steps in the nucleus and cytoplasm. The karyopherin Exportin 5 mediates their transport across the nuclear envelope and is essential for miRNA-dependent repression (Yi et al. 2003), and overexpression experiments suggest that it may be a limiting component of the pathway (Yi et al. 2005). In human cells, the Argonaute Ago2 has been shown to localize to the nucleus in an Importin 8-dependent manner, an activity that influences its ability to repress many targets, although the mechanism is not yet well defined (Weinmann et al. 2009). Not surprisingly, RNAi silencing pathways that operate specifically in the nucleus have also evolved ways of directing components to this compartment (for a review, see Ketting 2011). A notable example is the C. elegans Argonaute NRDE-3, which binds siRNAs in the cytoplasm and transports them to the nucleus, where it can silence corresponding genes undergoing transcription elongation (Guang et al. 2008, 2010). Analogously, the Tetrahymena Argonaute Twilp binds to siRNAs in the cytoplasm and carries them into the nucleus with essential help from the binding protein Giwlp, which appears to sense successful conversion of siRNAs from a duplex to single-stranded form (Noto et al. 2010).

In $S$. pombe cells, siRNAs are currently only known to be generated and function within the nucleus. Nevertheless, Bühler and colleagues (Emmerth et al. 2010; Barraud et al. 2011) have reported that Dcr1 has the potential to shuttle between the nucleus and cytoplasm and that a C-terminal zinc coordination motif and a dsRNA-binding domain (dsRBD) orchestrate its nuclear retention. Within the nucleus, overexpressed Dcr1 resides in NPC-proximal foci, and deletion of the $\mathrm{C}$ terminus suggests that this localization is critical for heterochromatic silencing of the centromeric repeats (Emmerth et al. 2010). It has remained unclear, however, whether the nuclear retention mechanism is actively exploited by the cell to regulate Dcr1 activity or whether the apparent association of Dcrl with the NPC is physiologically relevant.

In their new study, Woolcock et al. (2012) present significant advances on both of these fronts. First, their genome-wide DamID analyses reveal a very strong cor- 
relation between the genomic sites bound by Dcr1 and the nucleoporin Nup85, but not Amo1, a perinuclear protein not associated with the NPC. The average Dcr1- and Nup85-binding positions relative to ORF start sites also match exquisitely well, with association occurring preferentially upstream. Together, these observations argue that the NPC-proximal localization of Dcrl may guide it specifically to Nup85-bound target loci, bypassing Ago1 and small RNAs as determinants of sequence specificity (see above). A second major insight into Dcrl subcellular localization comes from differential scanning fluorimetry experiments in which the dsRBD critical for nuclear retention unfolds at high temperatures. Consistent with a previous mutational analysis of the dsRBD (Barraud et al. 2011), subjecting live cells to the temperatures that compromised the dsRBD structure also abrogated nuclear retention of overexpressed Dcr1. Although indirect effects are not ruled out, the data support an elegant model in which the effects of heat shock on Dcrl structure tip the balance toward cytoplasmic localization, with important consequences for silencing. In addition to the regulation of stress-inducible genes associated with NPCs (see below), this might also help explain an old observation that the canonical centromeric targets of Dcrl are derepressed at high temperatures (Allshire et al. 1994).

\section{RNAi-mediated silencing of protein-coding genes in fission yeast}

Although the molecular mechanisms of RNAi are widely conserved, its cellular roles are tremendously varied across species (Ketting 2011). One peculiarity of RNAi in S. pombe has been its apparent lack of protein-coding targets. Until recently, RNAi in fission yeast was not known to function outside the assembly of constitutive heterochromatin domains. Interestingly, convergent protein-coding gene pairs have been found to produce overlapping readthrough transcripts specifically in the short G1 stage of the $S$. pombe cell cycle. Transient heterochromatin develops in the corresponding intergenic regions in a manner that requires ago $^{+}$and $d c r 1^{+}$, suggesting that dsRNA may form and trigger RNAi-dependent regulation of these loci (Gullerova and Proudfoot 2008). As it turns out, many genes encoding RNAi components belong to convergent gene pairs, and their expression is autoregulated by this mechanism in a manner that is also critical for their role in centromeric silencing (Gullerova et al. 2011). In a distinct mechanism, Woolcock et al. (2012) identify as novel physiological targets of RNAi the class of genes bound by the stress response transcription factor Atf1. DamID shows that these loci are associated with NPCs and, under normal growth conditions, Dcr1, Rdp1, and Ago1. Importantly, expression analysis indicates that Dcr1, Rdp1, and Ago1 are all required for their repression. In at least some cases, RNA polymerase II occupancy is not affected by $d c r 1^{+}$ deletion, implying that repression occurs by both transcriptional gene silencing and CTGS. As a plausible mechanism for release of these genes from RNAi repression during heat shock, the investigators suggest cytoplasmic export of Dcr1 by temperature-induced structural changes in its $\mathrm{C}$ terminus (see above), and the genes are indeed constitutively derepressed in mutants of the Dcr 1 C terminus.

Intriguing differences stand out between the autoregulation of RNAi genes and the RNAi-mediated repression of Atf1-bound genes. First, autoregulated RNAi genes belong to convergent gene pairs; it is therefore their 3 ' ends that are targeted by the RNAi and heterochromatin components (Gullerova et al. 2011). In contrast, Atf1-bound genes are bound by the RNAi machinery predominantly at their promoters (Woolcock et al. 2012). This suggests that the mechanism repressing the latter genes intervenes earlier in the process of transcription to generate a dsRNA signal. A second, related difference is that silencing at convergent gene pairs relies on Dcrl and Ago1, but not Rdp1, contrary to Atf1-bound loci (Gullerova et al. 2011; Woolcock et al. 2012). Thus, whereas overlapping transcripts themselves are a sufficient source of dsRNA for regulation of convergent genes, stressinducible genes seem to require $\mathrm{Rdp} 1$ to synthesize the dsRNA trigger, presumably using a nascent transcript as a template. Silencing of the Atf1-bound genes resembles centromeric silencing in this regard, but paradoxically, heterochromatin is absent, as Swi6 is not enriched at these loci, and the H3K9 methyltransferase Clr4 is not required for Dcrl and Rdpl binding (Woolcock et al. 2012). However, the Clr4 enzymatic activity was recently shown to contribute to centromeric siRNA generation independently of H3K9 (Gerace et al. 2010), so the possibility remains to be tested that it might participate in euchromatic RNAi as well.

\section{Life beyond post-transcriptional gene silencing}

Despite its widespread conservation, the RNAi machinery has been lost in certain organisms such as Saccharomyces cerevisiae (Drinnenberg et al. 2009). In the evolution of $S$. pombe, RNAi was retained but acts primarily at the chromatin level. Mechanistically, the $S$. pombe variant of RNAi stands apart from canonical post-transcriptional gene silencing, which potently targets protein-coding genes for repression with the mere presence of dsRNA. $S$. pombe instead features transcriptional and cotranscriptional silencing pathways with intricate targeting requirements and a role mainly in repressing noncoding repeats. In this context, the regulation of Atf1-bound stress-inducible genes, whose initial physical targeting is surprisingly independent of small RNAs, represents a novel adaptive role for RNAi. In future studies, it will be interesting to see whether silencing within this broad class of genes occurs by a uniform mechanism. The new data (Woolcock et al. 2012) hint at the possibility that both transcriptional gene silencing and CTGS may be at work, depending on the locus. Given the absence of heterochromatin, this suggests the action of another transcriptional repression pathway yet to be determined. Additionally, the noncanonical poly(A) polymerase Cid14, which targets aberrant transcripts for exosomal degradation, is also enriched at these genes (Woolcock et al. 2012), so RNAi-independent RNA processing might also be involved. These and other new 
questions raised by this important work await further study.

\section{Acknowledgments}

We thank the National Institutes of Health (D.M.) and the National Science Foundation (graduate research fellowship to D.H.) for support. D.M. is an Investigator of the Howard Hughes Medical Institute.

\section{References}

Allshire RC, Javerzat JP, Redhead NJ, Cranston G. 1994. Position effect variegation at fission yeast centromeres. Cell 76: 157-169.

Barraud P, Emmerth S, Shimada Y, Hotz H, Allain FH, Bühler M. 2011. An extended dsRBD with a novel zinc-binding motif mediates nuclear retention of fission yeast Dicer. EMBO J 30: 4223-4235.

Bayne EH, Portoso M, Kagansky A, Kos-Braun IC, Urano T, Ekwall K, Alves F, Rappsilber J, Allshire RC. 2008. Splicing factors facilitate RNAi-directed silencing in fission yeast. Science 322: 602-606.

Bühler M, Moazed D. 2007. Transcription and RNAi in heterochromatic gene silencing. Nat Struct Mol Biol 14: 10411048.

Bühler M, Verdel A, Moazed D. 2006. Tethering RITS to a nascent transcript initiates RNAi- and heterochromatindependent gene silencing. Cell 125: 873-886.

Djupedal I, Kos-Braun IC, Mosher RA, Söderholm N, Simmer F, Hardcastle TJ, Fender A, Heidrich N, Kagansky A, Bayne E, et al. 2005. RNA Pol II subunit Rpb7 promotes centromeric transcription and RNAi-directed chromatin silencing. Genes Dev 19: 2301-2306.

Drinnenberg IA, Weinberg DE, Xie KT, Mower JP, Wolfe KH, Fink GR, Bartel DP. RNAi in budding yeast. 2009. Science 326: $544-550$.

Emmerth S, Schober H, Gaidatzis D, Roloff T, Jacobeit K, Bühler M. 2010. Nuclear retention of fission yeast Dicer is a prerequisite for RNAi-mediated heterochromatin assembly. Dev Cell 18: 102-113.

Fire A, Xu S, Montgomery MK, Kostas SA, Driver SE, Mello CC. 1998. Potent and specific genetic interference by doublestranded RNA in Caenorhabditis elegans. Nature 391: 806-811.

Gerace EL, Halic M, Moazed D. 2010. The methyltransferase activity of $\mathrm{Clr} 4^{\text {Suv39h }}$ triggers RNAi independently of histone H3K9 methylation. Mol Cell 39: 360-372.

Guang S, Bochner AF, Pavelec DM, Burkhart KB, Harding S, Lachowiec J, Kennedy S. 2008. An Argonaute transports siRNAs from the cytoplasm to the nucleus. Science 321: 537-541.

Guang S, Bochner AF, Burkhart KB, Burton N, Pavelec DM, Kennedy S. 2010. Small regulatory RNAs inhibit RNA polymerase II during the elongation phase of transcription. Nature 465: 1097-1101.

Gullerova M, Proudfoot NJ. 2008. Cohesin complex promotes transcriptional termination between convergent genes in S. pombe. Cell 132: 983-995.

Gullerova M, Moazed D, Proudfoot NJ. 2011. Autoregulation of convergent RNAi genes in fission yeast. Genes Dev 25: 556568.

Halic M, Moazed D. 2010. Dicer-independent primal RNAs trigger RNAi and heterochromatin formation. Cell 140: 504516.
Iida T, Nakayama J, Moazed D. 2008. siRNA-mediated heterochromatin establishment requires HP1 and is associated with antisense transcription. Mol Cell 31: 178-189.

Ketting RF. 2011. The many faces of RNAi. Dev Cell 20: 148-161.

Lejeune E, Allshire RC. 2011. Common ground: Small RNA programming and chromatin modifications. Curr Opin Cell Biol 23: 258-265.

Meister G, Tuschl T. 2004. Mechanisms of gene silencing by double-stranded RNA. Nature 431: 343-349.

Moazed D. 2009. Small RNAs in transcriptional gene silencing and genome defence. Nature 457: 413-420.

Motamedi MR, Verdel A, Colmenares SU, Gerber SA, Gygi SP, Moazed D. 2004. Two RNAi complexes, RITS and RDRC, physically interact and localize to noncoding centromeric RNAs. Cell 119: 789-802.

Noto T, Kurth HM, Kataoka K, Aronica L, Desouza LV, Siu KM, Pearlman RE, Gorovsky MA, Mochizuki K. 2010. The Tetrahymena argonaute-binding protein Giwlp directs a mature argonaute-siRNA complex to the nucleus. Cell 140: 692-703.

Schalch T, Job G, Noffsinger VJ, Shanker S, Kuscu C, Joshua-Tor L, Partridge JF. 2009. High-affinity binding of Chp1 chromodomain to $\mathrm{K} 9$ methylated histone $\mathrm{H} 3$ is required to establish centromeric heterochromatin. Mol Cell 34: 36-46.

Simmer F, Buscaino A, Kos-Braun IC, Kagansky A, Boukaba A, Urano T, Kerr AR, Allshire RC. 2010. Hairpin RNA induces secondary small interfering RNA synthesis and silencing in trans in fission yeast. EMBO Rep 11: 112-118.

Sugiyama T, Cam HP, Verdel A, Moazed D, Grewal SI. 2005. RNA-dependent RNA polymerase is an essential component of a self-enforcing loop coupling heterochromatin assembly to siRNA production. Proc Natl Acad Sci 102: 152-157.

Verdel A, Jia S, Gerber S, Sugiyama T, Gygi S, Grewal SI, Moazed D. 2004. RNAi-mediated targeting of heterochromatin by the RITS complex. Science 303: 672-676.

Volpe TA, Kidner C, Hall IM, Teng G, Grewal SI, Martienssen RA. 2002. Regulation of heterochromatic silencing and histone H3 lysine-9 methylation by RNAi. Science 297: 18331837.

Weinmann L, Höck J, Ivacevic T, Ohrt T, Mütze J, Schwille P, Kremmer E, Benes V, Urlaub H, Meister G. 2009. Importin 8 is a gene silencing factor that targets Argonaute proteins to distinct mRNAs. Cell 136: 496-507.

Wierzbicki AT, Ream TS, Haag JR, Pikaard CS. 2009. RNA polymerase $\mathrm{V}$ transcription guides ARGONAUTE4 to chromatin. Nat Genet 41: 630-634.

Woolcock KJ, Gaidatzis D, Punga T, Bühler M. 2011. Dicer associates with chromatin to repress genome activity in Schizosaccharomyces pombe. Nat Struct Mol Biol 18: 94-99.

Woolcock KJ, Stunnenberg R, Gaidatzis D, Hotz HR, Emmerth S, Barraud P, Bühler M. 2012. RNAi keeps Atf1-bound stress response genes in check at nuclear pores. Genes Dev 26: 683-692.

Yi R, Qin Y, Macara IG, Cullen BR. 2003. Exportin-5 mediates the nuclear export of pre-microRNAs and short hairpin RNAs. Genes Dev 17: 3011-3016.

Yi R, Doehle BP, Qin Y, Macara IG, Cullen BR. 2005. Overexpression of exportin 5 enhances RNA interference mediated by short hairpin RNAs and microRNAs. RNA 11: 220226. 


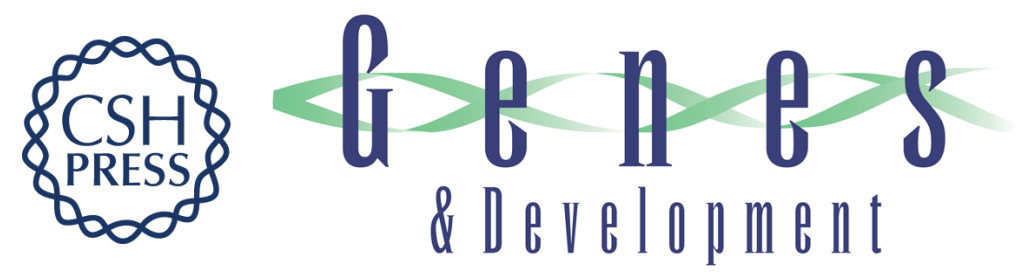

\section{RNAi in fission yeast finds new targets and new ways of targeting at the nuclear periphery}

Daniel Holoch and Danesh Moazed

Genes Dev. 2012, 26:

Access the most recent version at doi:10.1101/gad.191155.112

\section{Related Content RNAi keeps Atf1-bound stress response genes in check at nuclear pores Katrina J. Woolcock, Rieka Stunnenberg, Dimos Gaidatzis, et al. Genes Dev. April , 2012 26: 683-692 \\ References This article cites 33 articles, 11 of which can be accessed free at: http://genesdev.cshlp.org/content/26/8/741.full.html\#ref-list-1 \\ Articles cited in: \\ http://genesdev.cshlp.org/content/26/8/741.full.html\#related-urls \\ License \\ Email Alerting Receive free email alerts when new articles cite this article - sign up in the box at the top Service right corner of the article or click here.}

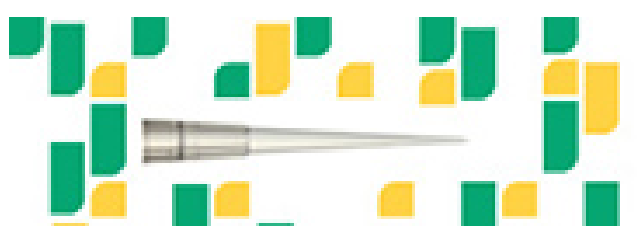

Focused on your science. 